\title{
Bullosis Diabeticorum
}

\section{Stephanie Parks Taylor, $M D^{7}$ and Kelli Dunn, $M D^{2}$}

'Department of Internal Medicine, Carolinas Medical Center, Charlotte, NC, USA; ${ }^{2}$ Endocrinology, Diabetes, and Metabolism, Carolinas Medical Center, Charlotte, NC, USA

KEY WORDS: bullosis diabeticorum; bullae; blistering diseases; diabetic complications.

$\mathrm{J}$ Gen Intern Med 32(2):220

DOI: $10.1007 / \mathrm{s} 11606-016-3802-3$

(c) Society of General Internal Medicine 2016

\begin{abstract}
A 65-year-old male with diabetes and peripheral neuropathy (last glycosylated hemoglobin level $9.4 \%$ ) reported spontaneous development of a $14 \times 9 \mathrm{~cm}$, tense bulla on the medial aspect of his right lower extremity (Fig. 1). The lesion was non-inflammatory in appearance with a non-erythematous base and clear serous content. Nikolsky's sign was negative. There were no other bullous skin lesions. The patient had no prior history of dermatologic disorders and denied any recent trauma, acute edema, or change in medications. The massive bulla spontaneously ruptured and healed without complication. The distribution and appearance of the bulla led to a clinical diagnosis of bullosis diabeticorum, a rare but likely underdiagnosed condition in patients with diabetes. Lesions appear rapidly, primarily in an acral distribution in areas of otherwise normal-appearing skin, and range from a few centimeters to very large. The differential diagnosis includes friction bullae, bullae due to burns or edema, bullous fixed drug reaction, bullous pemphigoid, and epidermolysis bullosa acquisita. Bullae resolve spontaneously but can recur, and secondary infection after rupture is a concern. The etiology of bullae formation in diabetics is unknown, although theories include microangiopathy ${ }^{1}$ and an enhanced vulnerability to trauma. ${ }^{2}$
\end{abstract}

Received May 4, 2016

Revised June 8, 2016

Accepted June 27, 2016

Published online July 11, 2016

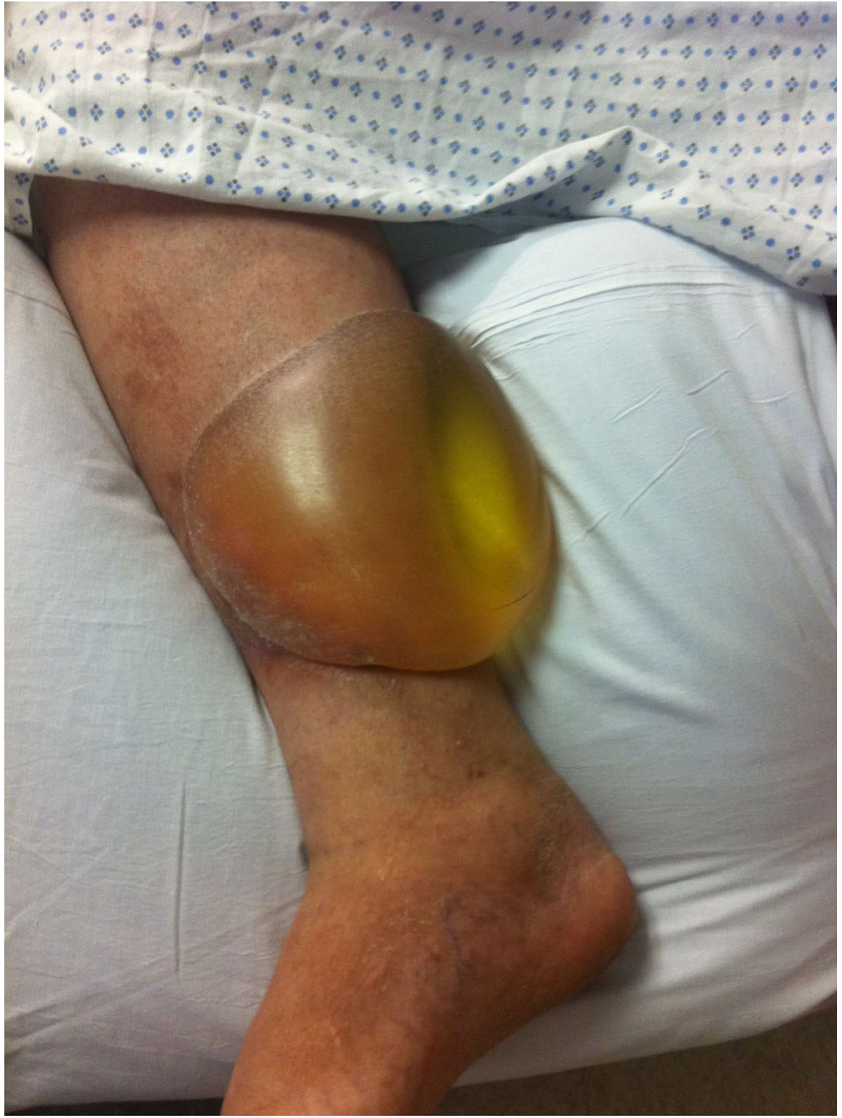

Figure 1. Large, tense bulla on the lower extremity.

Corresponding Author: Stephanie Parks Taylor, MD; Department of Internal Medicine Carolinas Medical Center, 1000 Blythe Blvd Suite 507, Charlotte, NC 28203, U S A (e-mail: Stephanie.p.taylor@carolinashealthcare.org).

\section{Compliance with Ethical Standards:}

Conflict of Interest: The authors declare that they do not have a conflict of interest.

\section{REFERENCES}

1. Derighetti M, Holhl D, Krayenbuhl BH, Panizzon RG. Bullosis diabeticorum in a newly discovered type 2 diabetes mellitus. Dermatology. 2000;200:366-7.

2. Bernstein JE, Levine LE, Medenica MM, Yung CW, Soltani K. Reduced threshold to suction-induced blister formation in insulin-dependent diabetics. J Am Acad Dermatol. 1983;8:790-1. 